\title{
Chapter 12 \\ Palaeogeographic-Analysis Approaches to Transport and Settlement in the Dutch Part of the Roman Limes
}

\author{
Mark R. Groenhuijzen
}

\begin{abstract}
The aim of the $\mathrm{PhD}$ research on which this chapter is based is to reconstruct and analyse the cultural landscape of the Dutch limes area using computational approaches, specifically to model and analyse transport networks, settlement patterns and their relationship with the natural environment, to better understand the interactions between the Roman military population and the local population that lived in this frontier region. The goal of this chapter is to present the general results of this study and showcase the technical, methodological and interpretative aspects that it has contributed to the research field of computational archaeology and to the archaeological understanding of the Dutch part of the Roman limes.
\end{abstract}

Keywords LCP analysis · Network science · Network analysis · Palaeogeography - Transport networks

\subsection{Introduction}

\subsubsection{General Introduction}

The main aim of the 'Finding the limits of the limes' project is to reconstruct and understand the cultural landscape of the Dutch part of the Roman limes, specifically looking at the spatial and economic interactions between the Roman military population and the local population. The spatial component is evidently an important part of the research project, and the palaeogeographic analysis of the Dutch limes area thus became the main focus of the $\mathrm{PhD}$ thesis on which this chapter is based (Groenhuijzen 2018). The general aim of this $\mathrm{PhD}$ study was to reconstruct and analyse the cultural landscape of the Dutch limes area using computational approaches; more specifically, it models and analyses transport networks and settlement patterns and includes their relationship with the natural environment.

M. R. Groenhuijzen $(\bowtie)$

Faculty of Humanities, Vrije Universiteit Amsterdam, Amsterdam, The Netherlands

e-mail: m.r.groenhuijzen@vu.nl 
This chapter will present the general results of the aforementioned $\mathrm{PhD}$ study and place it in the wider research context. It aims to showcase some of the innovative aspects of the study, either from technical, methodological or interpretative viewpoints. To do this, case studies from this $\mathrm{PhD}$ study in the realm of transport networks and settlement location in the Dutch part of the Roman limes are utilised. The questions that form the basis of these case studies are: how were goods transported from the local population to the military population, and what is the role of stone-built rural settlements in these transport networks; can location preferences shed light on the interaction between the local population and the military population?

Formulated in a more general question, the goal of this chapter is as follows: what has this spatial analytical study of the cultural landscape of the Dutch limes area contributed to the research field of computational archaeology and related fields, and what has it contributed to the archaeological understanding of the Dutch part of the Roman limes? Furthermore, what are the prospects for future research?

\subsubsection{Palaeogeographic Analysis of the Dutch Limes Area}

The palaeogeographic analysis of the Dutch part of the Roman limes that is performed as a $\mathrm{PhD}$ study within the 'Finding the limits of the limes' project can be subdivided into three parts: firstly, a reconstruction of the natural palaeogeography of the Rhine-Meuse delta in the Roman period; secondly, a reconstruction and analysis of local transport networks; and thirdly, an analysis of settlement location in the landscape. This section provides a summary of these three branches of the study, with more elaboration on the analyses and results and their place in the wider research context presented in the following sections.

In order to understand spatial developments and patterns in the cultural landscape in relation to the natural landscape, the natural landscape must be accurately known first. There is a strong tradition of reconstructing the natural environment in the Netherlands (e.g. Cohen et al. 2012; Vos 2015), and for the Roman period a great advance was made following the study of Van Dinter (2013) on the Old Rhine area between Utrecht and Katwijk. Using a similar methodology, this study has extended the 1:50,000 reconstruction of Van Dinter to cover the entire Rhine-Meuse delta, the geographic area roughly equal to what is considered the Dutch part of the Roman limes.

Transport as part of the cultural landscape is often understudied in archaeology, both due to the focus on settlements in archaeology and due to the immaterial nature of transport, particularly that of transport on the local scale. However, when we are interested in the interaction between the local and the Roman military population, most transport occurs on the local scale. In this research, computational modelling approaches are used to study local transport networks. A least-cost path (LCP) approach is applied to reconstruct local transport connections (e.g. Groenhuijzen and Verhagen 2015), and concepts of network science and formal network analysis 
are applied to reconstruct and analyse local transport networks (e.g. Groenhuijzen and Verhagen 2016,2017). The resulting networks are used to study archaeological questions such as the provisioning of the Roman military population from the local population and the potential role of intermediary sites in such provisioning networks. A significant part of the $\mathrm{PhD}$ study was focussed on local transport networks, and this aspect thus serves as the largest contribution to this chapter.

The study on the location of settlements in the landscape has had a traditional following in processual archaeology and predictive modelling (e.g. Brandt et al. 1992; Verhagen 2007). Most focus has traditionally been on site location in the natural landscape, but other aspects may also have played a role, among them (distance to) forts, transport networks and the influence of the historical landscape (e.g. Nuninger et al. 2016). This study has used a multivariate approach (e.g. Stančič and Veljanovski 2000; Fernandes et al. 2011; Chap. 9, Weaverdyck) to find how these various factors determined the location of rural settlements.

\subsection{Natural Palaeogeography}

The Rhine-Meuse delta in the Netherlands is a highly dynamic region, and the modern landscape is hardly a representative of the Roman landscape. To reconstruct the natural palaeogeography of the Dutch part of the Roman limes, a methodology was adopted from Van Dinter (2013). For the central part of the Dutch limes area this involves the manual combination of various source datasets in a GIS, ranging from geomorphological maps, soil maps, elevation maps, earlier palaeogeographic reconstructions and data from archaeological research. For the eastern part of the study area, this methodology is less applicable because the corridor through which the Rhine and Meuse move is narrower here, resulting in more erosion and burial of older channel belts. Therefore, a simple overlay of the existing geomorphological and palaeogeographic maps was used. The reconstructed natural palaeogeography represents the landscape roughly around CE 100 (Fig. 12.1a).

From a technical and methodological point of view, the reconstruction of the natural landscape for archaeological analysis is not innovative. A number of palaeogeographic datasets were already developed in the Netherlands, but they are often either on a coarse $(1: 500,000)$ national scale (e.g. Vos and De Vries 2013) or on a local scale (e.g. Vos and Gerrets 2005; Cohen et al. 2009), sometimes focussed on particular geomorphological elements rather than the landscape as a whole. Van Dinter (2013) provided a reconstruction that is suitable for the required level of analysis at the local and regional level, which is why this methodology was also used for extending the reconstruction to encompass the entire Dutch limes area.

Large yet detailed palaeogeographic reconstruction allows for analyses of archaeological phenomena on an unprecedented scale. Examples include the reconstruction of transport connections (Sect. 12.3; Groenhuijzen and Verhagen 2015; Van Lanen et al. 2016), the modelling of agricultural production (Van Dinter et al. 2014; Chap. 7, Joyce) and site location analysis (Sect. 12.4; Verhagen et al. 2016). 

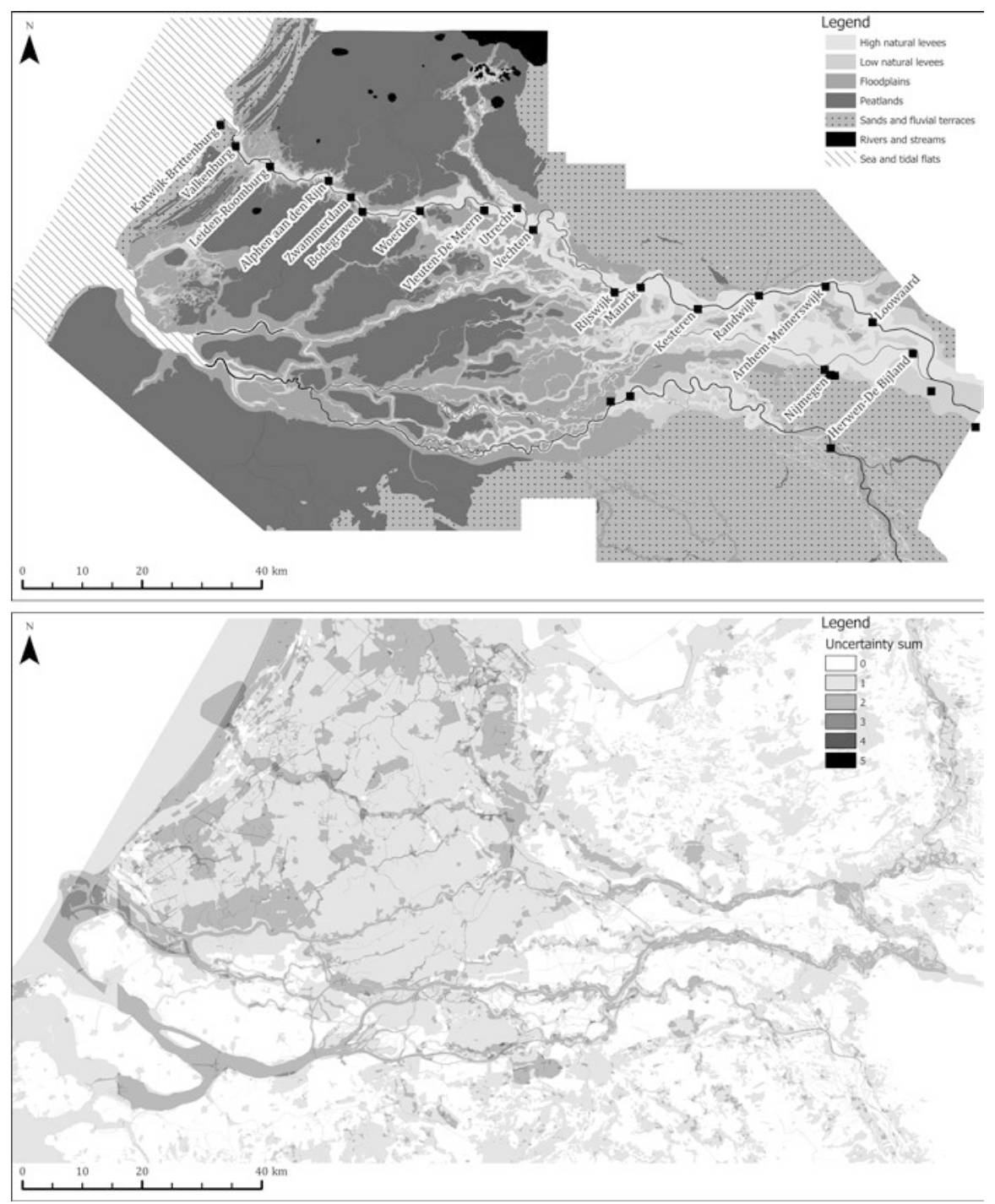

Fig. 12.1 (a) Natural palaeogeographic reconstruction (simplified) with diachronic overview of Roman fort locations. (b) Cumulative uncertainty map associated with the natural palaeogeographic reconstruction

The value of such reconstructions for archaeological research has become more prominent in the Netherlands in recent years, also outside the 'Finding the limits of the limes' project (e.g. Pierik 2017; Van Lanen 2017; De Kleijn et al. 2018).

An additional advantage to performing the detailed palaeogeographic reconstruction in a GIS is the ability to incorporate other information alongside the reconstruction. One important factor which is often overlooked in analyses using 
reconstructed landscapes is the uncertainty of the reconstruction itself. For the Rhine-Meuse delta, such uncertainty can come from post-Roman fluvial erosion, drift sand activity, peat reclamation or excavation and anthropogenic developments. By mapping the sources of uncertainty, a cumulative uncertainty map can be generated that can be used in further analyses (Fig. 12.1b), for example to filter the site dataset to only include those for which the palaeogeographic information is relatively certain, as has been done for the settlement location analysis (Sect. 12.4).

\subsection{Transport Networks}

\subsubsection{Introduction}

The study of mobility and transport in the Roman period has traditionally been focussed on the regional to empire-wide scale and particularly on shipping in the Mediterranean and on the military road networks, including that in the Netherlands (e.g. Scheidel 2014; Van der Heijden 2016). In comparison, fairly little research has been done on transport on the local to intraregional scales, mainly due to the lack of archaeologically visible local road systems.

In order to bridge this gap of knowledge, computational approaches have become increasingly popular, and the basic parameters of movement are rather well understood (Murrieta-Flores 2010; Polla and Verhagen 2014). Most computational approaches apply least-cost path (LCP) modelling, since this method allows for the incorporation of various cost components, for example regarding ancient topography. However, until recently, most applications of LCP modelling in the study of movement have been done to reconstruct single routes or small sets of routes or to identify the factors involved in establishing routes (e.g. Bell and Lock 2000; Llobera 2000; Zakšek et al. (2008); Verhagen 2013). The majority of LCP studies utilises elevation/slope as the main component and only models walking (Herzog 2014), and there are many functions available to do this analysis (Herzog 2013a). Applications that use other cost components are sparse, however (e.g. Livingood 2012; Verhagen 2013), as is the application of LCP modelling on other modes of transport (e.g. Wheatley and Gillings 2002; Verhagen et al. 2014).

Networks have become a common concept in archaeology, and over the last decade the use of network science in computational archaeology has grown in popularity (Brughmans 2013a). The formal study of sets of LCPs as networks however has thus far only been explored in a limited way, even though the application of formal network analysis techniques has shown to offer additional information that cannot be deduced from LCP maps qualitatively (e.g. Verhagen et al. 2013). 


\subsubsection{Modelling Transport}

In order to study transport in the Dutch limes area, transport connections between all settlements were modelled in Python using a LCP approach. Since the RhineMeuse delta has fairly little topographical relief, the impact of terrain conditions on movement is more important than that of slope. The formula (Eq. 12.1) provided by Pandolf et al. (1977) allows for the calculation of walking speed ( $V$ in $\mathrm{m} / \mathrm{s}$ ) while incorporating the walker's weight ( $W$ in $\mathrm{kg}$ ), carried load $(L$ in $\mathrm{kg})$, standard metabolic rate $(M$ in $\mathrm{W})$ and the natural terrain through a terrain coefficient $(\eta)$, with the coefficients provided by Soule and Goldman (1972). LCPs could thus be modelled using the reconstructed natural palaeogeography, resulting in a more accurate representation of local transport in the Dutch limes area (Groenhuijzen and Verhagen 2015).

$$
V=\sqrt{\frac{M-1.5 W-2.0(W+L)\left(\frac{L}{W}\right)^{2}}{1.5 \eta(W+L)}}
$$

Furthermore, the Pandolf et al. (1977) formula allows for the incorporation of varying weights of the carried load. It was found that this has a significant impact on how people could move through the landscape and particularly the time it takes to move. In general, movement with animal-drawn carts is slower and less forgiving for difficult terrains, which results in different properties of the transport networks that were constructed afterwards (Groenhuijzen and Verhagen 2015).

Besides walking, other modes of transport must also have played a role in the local transport system of the Dutch limes area. Animal-drawn carts were modelled using LCPs, with the costs based on functions provided by Raepsaet (2002). The modelled routes tend to avoid the wetter parts of the landscape, with most movement occurring on the higher and drier levees.

Little is known about local-scale transport infrastructure, likely largely due to the immaterial nature of the routes (Willems 1986). However, a comparison with the known infrastructure, namely the military road along the Rhine, is possible. Interestingly enough, a comparison of the modelled routes with an archaeological reconstruction of the road and potential secondary routes in the direct hinterland (Vos 2009) shows that the modelled routes largely concentrate outside the military road, and actually quite closely align with the assumed secondary routes (Fig. 12.2). Based on the LCP analysis performed in this study, the conclusion can be drawn that the military road thus seems to be largely peripheral to the majority of local-scale interactions (Groenhuijzen and Verhagen 2015).

In addition to land-based transport modes, the local and military population also made use of water-based transport options, as has been attested by a number of dugouts and larger river ships that have been found in the research area (e.g. Jansma and Morel 2007). This study has modelled dugouts as the main representative of 


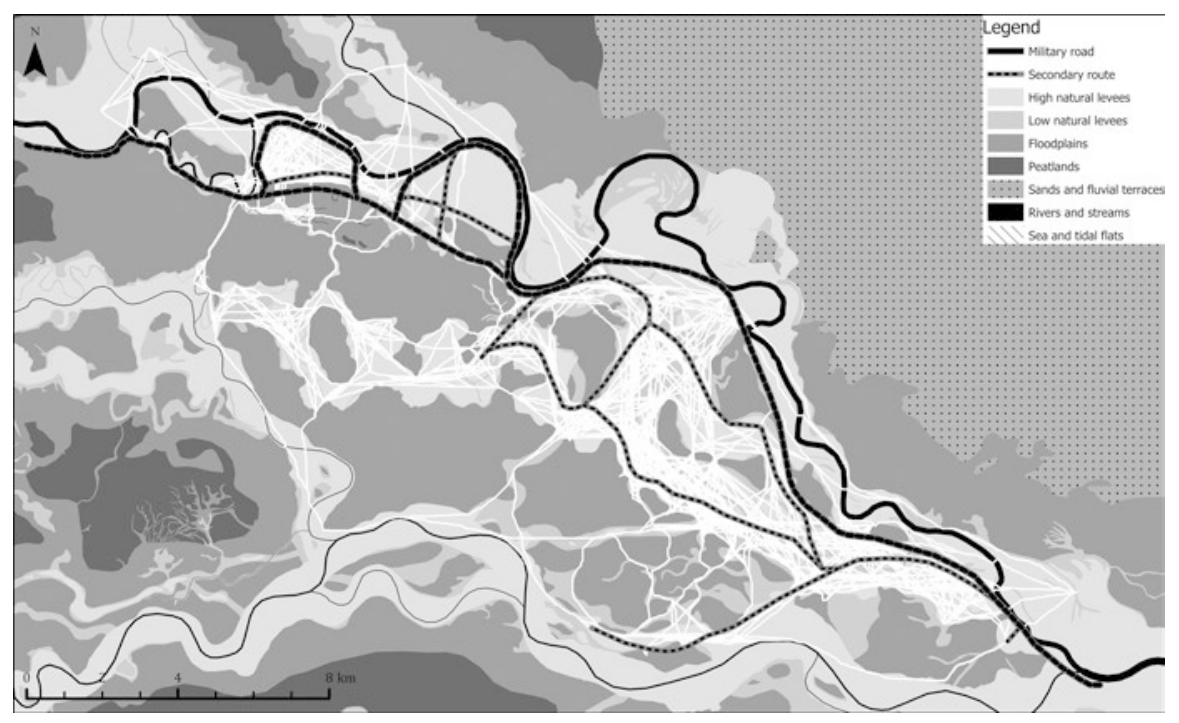

Fig. 12.2 Comparison of ox-cart-based transport connections modelled through LCP analysis (white lines) with the archaeological reconstruction of the military road and possible secondary routes (Vos 2009)

water-based transport on the local scale using experimental data (Gregory 1997). One of the problems when modelling water-based transport using a LCP approach is that in reality it is not possible to easily transfer between land- and water-based modes, and it is probably not possible at every location along a waterway. It is largely unknown where potential transfer places in the Rhine-Meuse delta would be, which means that the routes modelled through LCP analysis may not be the most realistic.

Through modelling multimodal routes between settlements in the research area (combining land- and water-based transport) it was found that some routes preferred waterways over land-based routes, but the majority of movement still followed the levees rather than water. This is likely due to the location of rivers: they are largely peripheral to local scale transport, and flow in an east-west direction, whereas a fair share of movement is south-north directed (or vice versa), particularly when moving from settlements in the hinterland towards the forts along the Rhine.

In general, the modelling of local transport connections through a LCP approach in this PhD study was successful in terms of understanding the interaction between movement and the natural environment. However, the modelling of movement on foot remains more reliable than those of animal-based or water-based transport modes. The former has a stronger tradition in physiological and archaeological research, whereas animal- and water-based transport models have to rely on fewer and less compatible sources to the situation of the Dutch Rhine-Meuse delta (e.g. in terms of terrain factors for carts or the influence of rivers on dugouts). The modelling of alternative means of transport thus remains a valuable avenue for future research. 


\subsubsection{Constructing Networks}

Modelled local transport connections do not readily tell anything about the functioning of transport in the Roman period, for example regarding questions such as the movement of surplus production from the rural settlements to the Roman military population. In order to address such questions, an additional step has to be undertaken to convert the dataset of transport connections modelled through LCP analysis into local transport networks.

However, earlier LCP network studies have given little thought to the choice of network structure (Herzog 2013b, c). Rivers et al. (2013) argue this choice must be based on the suitability for the archaeological record that the network structure aims to represent. To address this, a comparison was made between network construction techniques with the aim to find the best representation of a local provisioning system that connects the rural settlements to the Roman military population in the forts (Groenhuijzen and Verhagen 2017).

The network construction techniques compared were maximum distance networks, proximal point networks, a Delaunay triangulation, a Gabriel graph (Gabriel and Sokal 1969) and efficiency networks (Fulminante et al. 2017). The networks were evaluated on the criteria that all forts have a sufficient amount of settlements connected to it (either directly or indirectly), that the network does not contain too many connections, and that the forts are relatively easily accessible so that provisioning could be carried out relatively efficiently. The latter was measured through 'local' average path length, which is the average path length calculated from a limited number of nearest settlements to each fort. It was found that the Gabriel graph was the best representation of a local transport network functioning as a provisioning system connecting the rural settlements to the forts (Fig. 12.3 and Table 12.1). It had a relatively low 'local' average path length without creating too many connections. It was matched by some proximal point networks, but only for those that had an unrealistically high number of neighbours, and the Delaunay triangulation, which was disregarded on the basis of the inclusion of a number of unrealistic longdistance connections (Groenhuijzen and Verhagen 2017).

Besides finding a network structure that best represents a local transport network for the Dutch limes area, this study has confirmed the position of Rivers et al. (2013) that the choice of network construction technique is important and must be consciously based on the archaeological case it aims to represent, and it has presented a strategy through which such a decision can be made (Groenhuijzen and Verhagen 2017).

Additionally, this study has found that the application of LCPs instead of regular geodesic connections to construct networks has a significant impact on the resulting networks and the conclusions that can be drawn from them, for instance with the maximum distance network replacing the proximal point network as the most efficient one in terms of 'local' average path length (Table 12.1). This shows that incorporating the natural terrain, in this case through a LCP approach, can be important 


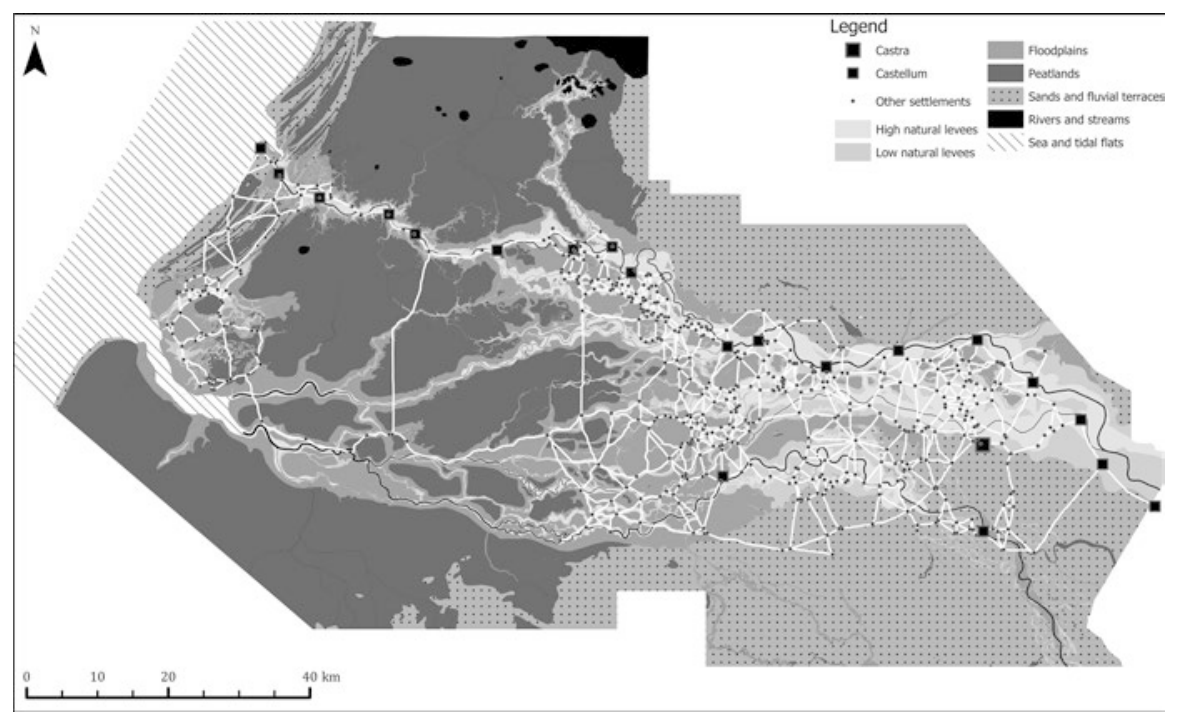

Fig. 12.3 Gabriel graph network of transport connections modelled through LCP analysis (white lines), based on walking while carrying a load of $20 \mathrm{~kg}$ in the Middle Roman Period A

Table 12.1 Average of the 'local' average path lengths (in minutes) to the forts from the nearest 25 settlements, shown in a comparison between temporal distances derived from LCPs and geodesic distances

\begin{tabular}{|c|c|c|c|}
\hline & $\begin{array}{l}\text { Temporal distances (derived } \\
\text { from LCP) }\end{array}$ & $\begin{array}{l}\text { Geodesic } \\
\text { distances }\end{array}$ & Difference \\
\hline Max. distance (90 min.) & & 85.4 & \\
\hline Max. distance (120 min.) & 124.5 & 84.2 & $\begin{array}{l}+44.0 \% \\
\pm 12.4 \%\end{array}$ \\
\hline \multicolumn{4}{|l|}{$\begin{array}{l}\text { Proximal point ( } 3 \\
\text { neighbours) }\end{array}$} \\
\hline $\begin{array}{l}\text { Proximal point ( } 5 \\
\text { neighbours) }\end{array}$ & 127.6 & 92.8 & $\begin{array}{l}+36.9 \% \\
\pm 13.9 \% \\
\end{array}$ \\
\hline $\begin{array}{l}\text { Proximal point ( } 7 \\
\text { neighbours) }\end{array}$ & 120.7 & 87.0 & $+37.5 \% \pm 6.2 \%$ \\
\hline Delaunay triangulation & 121.2 & 86.7 & $+39.0 \% \pm 6.4 \%$ \\
\hline Gabriel graph & 130.0 & 94.1 & $+37.6 \% \pm 7.3 \%$ \\
\hline Minimum spanning tree & 170.1 & 123.5 & $+36.6 \% \pm 5.4 \%$ \\
\hline $\begin{array}{l}\text { Efficiency }(10 \% \text { size } \\
\text { increase) }\end{array}$ & 143.5 & 107.6 & $+33.4 \% \pm 6.1 \%$ \\
\hline $\begin{array}{l}\text { Efficiency ( } 25 \% \text { size } \\
\text { increase) }\end{array}$ & 139.7 & 101.9 & $+38.1 \% \pm 7.1 \%$ \\
\hline $\begin{array}{l}\text { Efficiency (50\% size } \\
\text { increase) }\end{array}$ & 134.0 & 97.1 & $+38.1 \% \pm 5.7 \%$ \\
\hline
\end{tabular}

LCPs are based on walking while carrying a load of $20 \mathrm{~kg}$. Missing values are the result of forts not being reachable by at least 25 settlements. (Groenhuijzen and Verhagen 2017) 
for better understanding how transport worked or, more generally, how space was utilised in the past (Groenhuijzen and Verhagen 2017).

Using the LCP-based networks, archaeological questions can be addressed through formal network approaches. However, the various uncertainties involved in even reaching this step are often overlooked. These uncertainties, for example, may be the result of the chosen software (Gietl et al. 2008), the methods for calculating the costs of movement (Herzog 2013a) or the sources on which these costs are based (Herzog and Posluschny 2011) which have been treated to some extent in the given references. Since the current approach constructs networks on the basis of LCPs between settlements, the settlement dataset itself is another important source of uncertainty. In general, past studies in network analysis of transport in archaeology have paid little attention to the validation of results, even though network measures can become less stable when the data is imperfect (Borgatti et al. 2006) or when sampling the network dataset (Costenbader and Valente 2003). To address this potential problem, a robustness analysis was applied on local network metrics in the constructed network (Groenhuijzen and Verhagen 2016).

The robustness analysis was carried out in a model written in NetLogo (Wilensky 1999), a software package not commonly used for network analysis but useful through its easy accessibility and parallel processing capabilities. In the model, a single network was repeatedly constructed from scratch by iteratively adding sites to the network, and recalculating the local network measure of betweenness centrality. By tracking the development of this measure throughout the iterative construction of the network, a stabilisation point can be established, i.e. the point at which the measure has reached the value it retains until the network is fully constructed. If this happens well before the network is complete, the network measure on this site could thus be considered relatively robust (Groenhuijzen and Verhagen 2016).

The study found that $64 \%$ of all sites in the network have a betweenness centrality measure that is relatively robust. This rises to $81 \%$ when only considering sites that have a high betweenness centrality, which from an archaeological point of view are often considered to be important sites in the network, as a high betweenness centrality indicates a high amount of control over the network. These results have implications for the application of network analysis on archaeological networks; while a majority of sites is relatively robust (i.e. not susceptible to slight changes in the site dataset) and thus is trustworthy enough to warrant an archaeological interpretation regarding roles in the network, this is not the case for a considerable amount of other sites (Groenhuijzen and Verhagen 2016).

\subsubsection{Applications}

After the construction of a network, the dataset of settlements and modelled transport connections becomes accessible to a more quantitative study in the form of network analysis. In this research, two studies have been carried out in the context of the Dutch limes area. Firstly, how were goods moved from the local population 
to the military population? Secondly, what is the role of stone-built rural settlements, a small subset of the rural settlement dataset, in transport networks? Since the Gabriel graph was found to be the best representation of a local transport network (Groenhuijzen and Verhagen 2017), this network structure was used to model local transport networks from the LCP dataset. The rural settlement dataset was filtered for chronological reliability using the methodology described by Verhagen et al. (2016), resulting in a diachronic dataset of 636 sites (58\% of the original size). Per time period, the number of rural settlements ranges between 284 (Late Iron Age) and 587 (Middle Roman Period B).

Regarding the first question, two contrasting hypotheses were posed: one in which all goods flowed from each rural settlement directly to the nearest fort, and an alternative one in which goods were gathered at an intermediary site before moving in bulk to the fort (a dendritic hierarchic system, cf. Willems 1986; Vos 2009). The premise of the latter hypothesis is that the most ideal gathering point is on average 'closer' to the rural settlements than the forts themselves. As potential intermediary sites, a selection was made of towns, vici, stone-built rural settlements, large rural settlements and settlements containing horrea (warehouses, often granaries, but could also be used for other goods). The hypotheses were tested using the network measure of path length, expressed in minutes of travel time over the links in the network (derived from the LCPs). For the alternative hypothesis to be valid, the sum of the path lengths $(L)$ to reach the intermediary site $(i)$ from a number of settlements $(s)$ in addition to the path length of the intermediary site to the fort $(f)$ should be lower than the sum of the path lengths to reach the fort directly (Eq. 12.2). Since provisioning is more likely to occur from the settlements that are near than ones that are further away, the total path length was calculated for the 25 nearest settlements.

$$
\begin{gathered}
\mathrm{TPL}_{\text {intermediary }}<\mathrm{TPL}_{\text {fort }}, \text { where : } \\
\mathrm{TPL}_{\text {fort }}=\sum_{s} L(s, f) \\
\mathrm{TPL}_{\text {intermediary }}=L(i, f)+\sum_{s} L(s, i)
\end{gathered}
$$

The results (Fig. 12.4) shed light on how the provisioning of the Roman army may have worked. Fairly little can be said about the western part of the Dutch limes area (corresponding to Katwijk-Brittenburg until Utrecht), since very few sites have been identified as potential intermediary sites. The few ones that are are so distant from the forts that they may have functioned as an intermediary site for more than one fort. In terms of total path length they are more efficient than the forts themselves as gathering sites, making the alternative hypothesis more likely. Additionally, it is possible that the forts themselves functioned as gathering places for their local area. In contrast, a large number of intermediary sites are available in the central part of the Dutch limes area (Vechten and Rijswijk). A number of these were found 


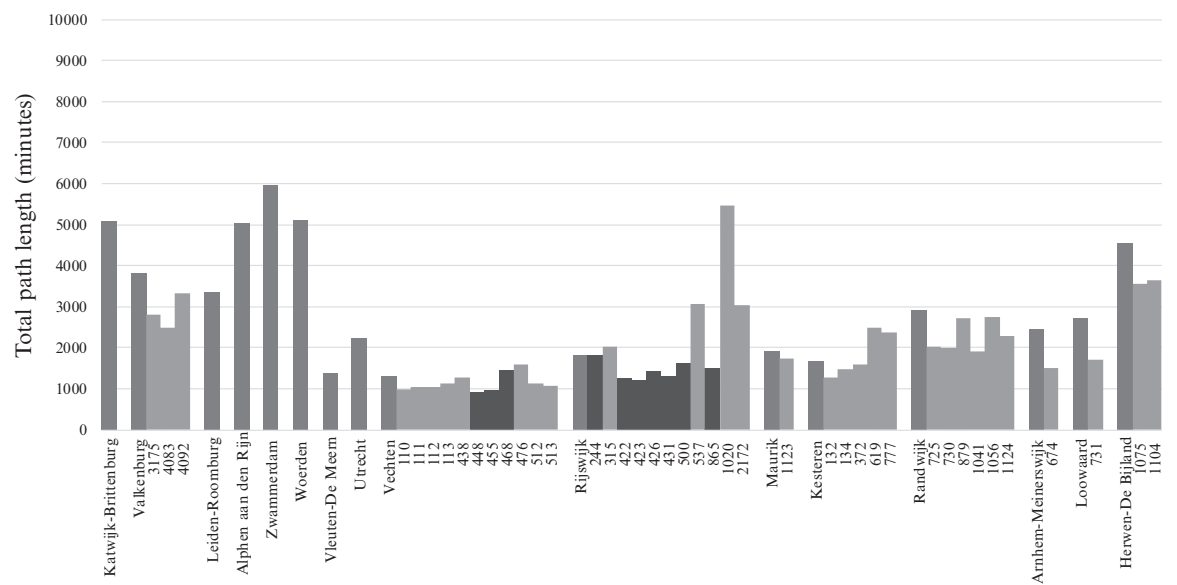

Fig. 12.4 Comparison of the total path length to reach forts against total path length to reach forts via the selected intermediary sites (alternative hypothesis), measured from the 25 nearest settlements in the network of walking while carrying a load of $20 \mathrm{~kg}$. The intermediary sites (light grey colours) are grouped by the nearest fort (dark grey colours), with 'large' rural settlements in the Kromme Rijn region shown through hatching. For locations see Fig. 12.1a

to have a lower total path length than the forts, although this is not true for all sites. Interestingly enough, almost all sites that have been identified as 'large' rural settlements (Vos 2009) have a lower total path length than the forts, whereas vici and some stone-built rural settlements do not. In the eastern part of the Dutch limes area (from Maurik to Herwen-De Bijland) almost all intermediary sites have a lower total path length than the forts, indicating that the alternative hypothesis is more likely in this area. The difference between the central and eastern parts may be caused by a more diffuse settlement pattern in the eastern part of the Dutch limes area; on an average, settlements in the central part are closer to the forts than in the eastern part. This could have resulted in an increased need for intermediary sites in a provisioning system in the eastern part of the Dutch limes area.

The second study revolved around the role of stone-built rural settlements in transport networks, more particularly, if the position of these settlements in transport networks may have led them to grow in importance and become stone-built. This was approached using the network measure of betweenness centrality, which represents the amount of control a site has over movement in the network. More explicitly, the question is thus if at any point in time (but especially before becoming stone-built) there is a notable/significant difference in betweenness centrality for the stone-built rural settlements compared to other settlements?

For this analysis, the stone-built settlements were compared to their ten nearest neighbours, since betweenness centrality is also dependent on the location of sites in the network as a whole, and it is more interesting to compare stone-built settlements to their nearest neighbours to see if they hold some remarkable position in the network. If the betweenness centrality was more than one standard deviation away 
from the mean betweenness centrality of its ten nearest neighbours, it was deemed to have occupied such a notable position in the network (Table 12.2).

For the Late Iron Age-Middle Roman Period B interval, roughly a third of stonebuilt rural settlements exceed the mean betweenness centrality of the ten nearest settlements by more than one standard deviation. This is more than would be expected, since at any time only 5-7\% of all rural settlements are (or would later become) stone-built. A total of 17 out of 33 stone-built rural settlements exceeded the mean by more than one standard deviation at any point in time, and only three did so in the Middle Roman Period at the latest. The other 14 settlements did so already in the Late Iron Age-Early Roman Period B interval. It can thus be interpreted that one of the reasons why these sites became stone-built in the Middle Roman Period is the potential for control that these sites have over movement in transport networks in the preceding time periods. This cannot be the only reason however, since there are 16 stone-built rural settlements that do not stand out from their neighbours, and likewise there are rural settlements that do stand out yet have never become stone-built.

Comparing the results of the second case study to the first one presented in this section, it was found that some stone-built settlements that do not stand out in terms of betweenness centrality were able to potentially fulfil their role as intermediary site in provisioning systems. This shows that a settlement may have become stonebuilt for more than one reason related to centrality in local transport networks: because it can be easily reached by other settlements, or because it needs to be traversed to reach other settlements.

\subsection{Settlement Location Analysis}

The location of settlements in the landscape has long been of interest to archaeologists, but many studies do not go much further than incorporating the natural terrain. Less frequently, other components are included, such as social, cultural or historical influences. This study has studied the location of settlements through a multivariate

Table 12.2 Total number of stone-built rural settlements per time period (n), and the numbers and percentage that have a betweenness centrality $\left(C_{B}\right)$ that is more than one standard deviation above the mean betweenness centrality of the ten nearest settlements

\begin{tabular}{l|l|l|l|l|l|l|l}
\hline & LIA & ERP A & ERP B & MRP A & MRP B & LRP A & LRP B \\
\hline$n$ & $18^{\mathrm{a}}$ & $20^{\mathrm{a}}$ & $21^{\mathrm{a}}$ & 27 & 32 & 23 & 23 \\
\hline $\mathrm{n}$ with $C_{B} \geq \overline{C_{B 10 \mathrm{nn}}}+\sigma_{10 \mathrm{nn}}$ & 7 & 5 & 8 & 8 & 8 & 5 & 3 \\
\hline \% with $C_{B} \geq \overline{C_{B 10 \mathrm{nn}}}+\sigma_{10 \mathrm{nn}}$ & 38.9 & 25 & 38.1 & 29.6 & 25 & 21.7 & 13.0 \\
\hline
\end{tabular}

LIA Late Iron Age, ERP Early Roman Period (A/B), MRP Middle Roman Period (A/B), LRP Late Roman Period (A/B)

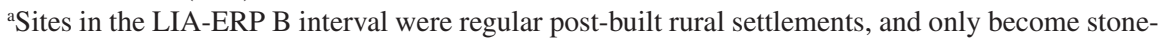
built in the MRP A 
approach, taking into account the natural palaeogeography, (distance to) rivers and streams, forts, transport networks (using the Gabriel graph constructed from the LCP dataset), potential intermediary sites in transport networks and the influence of the historical landscape (previously existing settlements). The question that is studied can be put quite simply as: what governed the location settlements in the Dutch Rhine-Meuse delta? However, since the primary interest of this research lies on the relation between the military and the rural population, the question can also be specified as: can the location preferences of rural settlements shed light on the interaction between the local population and the military population?

A binomial logistic regression was applied to investigate the relations between and the individual importance of the aforementioned variables for rural settlement location in the Dutch limes area. The dependent variable of the regression model is binary: a rural settlement is either present or absent. For this reason, 10,000 non-site locations were modelled to include in the dataset alongside the settlement locations. The rural settlement dataset itself was filtered for chronological reliability following the methodology outlined by Verhagen et al. (2016) and for spatial uncertainty (Sect. 12.2). This resulted in a diachronic dataset of 450 sites (41\% of the original size), mostly focussed on the Central and Eastern River Area.

Most parameters are relatively straightforward to implement, the exceptions being the natural palaeogeography and the historical landscape. A settlement location in the natural landscape is not just decided by the point location but also by what kind of landscape elements are available in its vicinity. To solve this, the natural palaeogeographic composition of each site's vicinity was calculated within a $500 \mathrm{~m}$ range, and cluster analysis was applied to create 'landscape types' (Verhagen et al. 2016). For the historical landscape, 'heritage maps' were created using an incremental kernel density approach following the methodology of Nuninger et al. (2016).

The logistic regression was applied with a Monte Carlo method approach for each time period, where in each of the simulation runs, half of the rural settlements during that time period were randomly selected as training dataset to fit the regression model, along with a set of non-sites of equal size. The other half of the rural settlements served as part of the testing dataset, again with an equal-sized set of non-sites. The testing dataset was used to assess the predictive capability of the model.

The logistic regression found that the historical landscape and distance to the transport networks were important factors for settlement location. The former indicates that sites are more likely to appear in areas where other sites are already present. Of course, the distance to transport networks goes hand in hand with the historical landscape; the transport networks are modelled on the basis of the settlements and thus tend to have a higher density in areas where site density is also higher, and thus the heritage factor is stronger. Furthermore, both the settlements and the transport network tend to concentrate on the levees. These variables thus strongly interact with each other and with the natural landscape (specifically the 'levees' category), which is evident also in this analysis. The other considered factors, namely, the distance to rivers and streams, forts and intermediary sites in 
transport networks, are not found to be important for the location of rural settlements in the Dutch limes area. An interpretation that can be attached to this is that the location of rural settlements is governed by landscape suitability and the potential to interact with other rural settlements, but not particularly to interact with the military population or with sites that may have accommodated interaction with the military population.

Furthermore, some interesting shifts were found in settlement location preferences through time. During two intervals within the Early Roman Period and Middle Roman Period there was a shift towards more 'marginal' areas, both in terms of the natural environment as well as the settlement landscape. This may be explained as a result of changing modes of production or as a result of increasing pressure in the core habitation area on the levees. The opposite trend is seen in the Late Roman Period, where new settlements tend to appear within the core habitation area rather than along the margins, perhaps because the lower population density did not necessitate such a move.

\subsection{Conclusions}

The LCP modelling, network studies and settlement location analysis presented above have provided some new and valuable insights into the properties of movement on the local scale in the Dutch Rhine-Meuse delta, the potential functioning of the Roman military provisioning system, the role of individual sites within these local transport networks and the relation between settlements and their natural and social environment. For example, the case studies applied on the modelled transport networks have found that at least for the eastern and central parts of the study area it is more likely that transport from the local to the military population was carried out through intermediary sites rather than through the forts, supporting the archaeological hypothesis of a dendritic hierarchic settlement system. Furthermore, the role that individual settlements have in these networks of transport could have given rise to the higher-status stone-built settlements, as some of these have been shown to be valuable as potential intermediary sites and/or to be centrally located on routes between other settlements. The settlement location analysis has found that settlements tend to concentrate on the levees in areas where settlements already existed previously and close proximity to transport networks. Other factors were less important, showing that the location of new settlements is mostly governed by landscape suitability and the potential to interact with other rural settlements and not particularly to interact with the military population. The findings stated above are valuable for archaeologists to further their thought on interactions between the local and military population of the Dutch limes area.

Of similar importance are the methods through which these results are achieved. By formulating the archaeological questions in such a way that they can be addressed by the computational approaches, these studies can provide new insights that were not readily extractable from the archaeological data beforehand. In contrast to 
tailoring an archaeological problem to the computational approach, which is sometimes offered as a criticism in some computational studies (e.g. Brughmans 2013b; Herzog 2014), formulating a question- or hypothesis-based approach and tailoring the computational approaches to that topic can add value to the application of computational approaches in archaeology.

More specifically tailored to the approaches applied in this research, the application of LCP analysis to model local transport connections has proven valuable, as it allows for the inclusion of the natural terrain, and this was found to have significant impacts on the following analyses. The application of network analysis on problems that are specifically suitable to be addressed as networks (such as questions on the Roman provisioning system) has proven to be valuable and lead to interesting archaeological conclusions, and the results of this research thus encourages similar future problems around transport to be addressed as networks as well.

Important in the application of computational approaches is the need to account for uncertainty in the data and methods and for the validation of the results. Wherever possible, in this research, it was attempted to take uncertainty into account, such as the spatial uncertainty of the natural palaeogeographic reconstruction (Sect. 12.2) and the chronological uncertainty in the site dataset (Verhagen et al. 2016). The results of the network analysis were subjected to a robustness analysis (Sect. 12.3.3; Groenhuijzen and Verhagen 2016), in order to make the interpretations drawn from these results more reliable. However, there is still more work to do in this area. Archaeological data is inherently uncertain and incomplete, and quantitative approaches thus remain susceptible to such data problems; this research only shows some ways in which these uncertainties can be incorporated into the research to strengthen the output.

\section{References}

Bell T, Lock G (2000) Topographic and cultural influences on walking the ridgeway in later prehistoric times. In: Lock G (ed) Beyond the map. Archaeology and spatial technologies. IOS Press, Amsterdam, pp 85-100

Borgatti SP, Carley KM, Krackhardt D (2006) On the robustness of centrality measures under conditions of imperfect data. Soc Networks 28:124-136. https://doi.org/10.1016/j. socnet.2005.05.001

Brandt R, Groenewoudt BJ, Kvamme KL (1992) An experiment in archaeological site location: modeling in the Netherlands using GIS techniques. World Archaeol 24:268-282. https://doi. org/10.1080/00438243.1992.9980207

Brughmans T (2013a) Networks of networks: a citation network analysis of the adoption, use, and adaptation of formal network techniques in archaeology. Lit Linguist Comput 28:538-562. https://doi.org/10.1093/llc/fqt048

Brughmans T (2013b) Thinking through networks: a review of formal network methods in archaeology. J Archaeol Method Theory 20:623-662. https://doi.org/10.1007/s10816-012-9133-8

Cohen KM, Stouthamer E, Hoek WZ, Berendsen HJA, Kempen HFJ (2009) Zand in banen. Zanddiefptekaarten van het Rivierengebied en het IJsseldal in de provincies Gelderland en Overijssel, 3rd edn. Provincie Gelderland, Arnhem 
Cohen KM, Stouthamer E, Pierik HJ, Geurts AH (2012) Rhine-Meuse delta studies' digital basemap for delta evolution and palaeogeography. Dept. Physical geography, Utrecht University, Utrecht

Costenbader E, Valente TW (2003) The stability of centrality measures when networks are sampled. Soc Networks 25:283-307. https://doi.org/10.1016/S0378-8733(03)00012-1

De Kleijn M, Beijaard F, Koomen E, Van Lanen RJ (2018) Simulating past land use patterns; the impact of Romans on the Lower Rhine delta in the first century AD. In: De Kleijn M (ed) Innovating landscape research through geographic information science. Implications and opportunities of the digital revolution in science for the research of the archaeology, history and heritage of the landscape from a GIScience perspective. Vrije Universiteit Amsterdam, Amsterdam, pp 125-148. Available at http://dare.ubvu.vu.nl/handle/1871/55517. Accessed on 7 June 2018

Fernandes R, Geeven G, Soetens S, Klontza-Jaklova V (2011) Deletion/substitution/addition (DSA) model selection algorithm applied to the study of archaeological settlement patterning. J Archaeol Sci 38:2293-2300. https://doi.org/10.1016/j.jas.2011.03.035

Fulminante F, Prignano L, Morer I, Lozano S (2017) Coordinated decisions and unbalanced power. How latin cities shaped their terrestrial transportation network. Front Digit Humanit 4. https:// doi.org/10.3389/fdigh.2017.00004

Gabriel KR, Sokal RR (1969) A new statistical approach to geographic variation analysis. Syst Zool 18:259-270. https://doi.org/10.2307/2412323

Gietl R, Doneus M, Fera M (2008) Cost distance analysis in an alpine environment: comparison of different cost surface modules. In Posluschny A, Lambers K, Herzog I (eds) Layers of perception: Proceedings of the 35th international conference on computer applications and quantitative methods in archaeology (CAA). Berlin, Germany, April 2-6, 2007, Dr Rudolf Habelt GmbH, Bonn, pp 316-321

Gregory NTN (1997) A comparative study of Irish and Scottish Logboats. University of Edinburgh, Edinburgh

Groenhuijzen MR (2018) Palaeogeographic analysis of the Dutch part of the Roman limes. Vrije Universiteit Amsterdam, Amsterdam

Groenhuijzen MR, Verhagen P (2015) Exploring the dynamics of transport in the Dutch limes. eTopoi J Anc Stud Spec 4:25-47. Available at http://journal.topoi.org/index.php/etopoi/article/ view/203/227. Accessed on 10 May 2018

Groenhuijzen MR, Verhagen P (2016) Testing the robustness of local network metrics in research on archeological local transport networks. Front Digit Humanit 3. https://doi.org/10.3389/ fdigh.2016.00006

Groenhuijzen MR, Verhagen P (2017) Comparing network construction techniques in the context of local transport networks in the Dutch part of the Roman limes. J Archaeol Sci Rep 15:235251. https://doi.org/10.1016/j.jasrep.2017.07.024

Herzog I (2013a) Theory and practice of cost functions. In Contreras F, Farjas M, Melero FJ (eds) Fusion of cultures. Proceedings of the 38th Annual conference on computer applications and quantitative methods in archaeology, Granada, Spain, April 2010. Archaeopress, Oxford, pp 375-382

Herzog I (2013b) Least-cost networks. In Earl G, Sly T, Chrysanthi A, Murrieta-Flores P, Papadopoulos C, Romanowska I, Wheatley D (eds) CAA2012. Proceedings of the 40th conference in computer applications and quantitative methods in archaeology, Southampton, United Kingdom, 26-30 March 2012. Pallas Publications, Amsterdam, pp 240-251

Herzog I (2013c) Review of least cost analysis of social landscapes. Archaeological case studies. Internet Archaeol 34. https://doi.org/10.11141/ia.34.7

Herzog I (2014) A review of case studies in archaeological least-cost analysis. Archeologia e Calcolatori 25:223-239. Available at http://www.archcalc.cnr.it/indice/PDF25/12_Herzog.pdf. Accessed on 10 May 2018

Herzog I, Posluschny A (2011) Tilt - slope-dependent least cost path calculations revisited. In: Jerem E, Redő F, Szeverényi V (eds) On the road to reconstructing the past. Computer applications and quantitative methods in archaeology (CAA). Proceedings of the 36th international conference. Budapest, April 2-6, 2008. Archaeolingua, Budapest, pp 212-218, Available at 
https://proceedings.caaconference.org/paper/cd31_herzog_posluschny_caa2008. Accessed on 26 July 2018

Jansma E, Morel JMAW (2007) Een Romeinse Rijnaak, gevonden in Utrecht-De Meern. Resultaten van het onderzoek naar de platbodem 'De Meern 1'. Rijksdienst voor Archeologie, Cultuurlandschap en Monumenten, Amersfoort

Livingood P (2012) No crows made mounds. In: White DA, Surface-Evans S (eds) Least cost analysis of social landscapes. Archaeological case studies. The University of Utah Press, Salt Lake City, pp 174-187

Llobera M (2000) Understanding movement: a pilot model towards the sociology of movement. In: Lock G (ed) Beyond the map. Archaeology and spatial technologies. IOS Press, Amsterdam, pp 64-84

Murrieta-Flores PA (2010) Traveling in a prehistoric landscape: exploring the influences that shaped human movement. In Frischer B, Webb Crawford J, Koller D (eds) Making history interactive. Computer applications and quantitative methods in archaeology (CAA). Proceedings of the 37th international conference, Williamsburg, Virginia, USA, March 22-26, 2009. Archaeopress, Oxford, pp 249-267. Available at https://proceedings.caaconference.org/ paper/31_Murrieta-Flores_CAA2009. Accessed on 26 July 2018

Nuninger L, Verhagen P, Bertoncello F, Castrorao Barba A (2016) Estimating 'land use heritage' to model changes in archaeological settlement patterns. In: Multi-, inter- and transdisciplinary research in landscape archaeology. Proceedings of LAC 2014 conference, Rome, 19-20 September 2014. Vrije Universiteit Amsterdam, Amsterdam. https://doi.org/10.5463/ lac. 2014.60

Pandolf KB, Givoni B, Goldman RF (1977) Predicting energy expenditure with loads while standing or walking very slowly. J Appl Physiol 43:577-581. https://doi.org/10.1152/ jappl.1977.43.4.577

Pierik HJ (2017) Past human-landscape interactions in the Netherlands: reconstructions from sand belt to coastal-delta plain for the first millennium AD. Utrecht University, Utrecht

Polla S, Verhagen P (eds) (2014) Computational approaches to the study of movement in archaeology. De Gruyter, Berlin. https://doi.org/10.1515/9783110288384

Raepsaet G (2002) Attelages et Techniques de Transport Dans Le Monde Gréco-Romaine. Le Livre Timperman, Brussels

Rivers R, Knappett C, Evans T (2013) What makes a site important? Centrality, gateways and gravity. In: Knappett C (ed) Network analysis in archaeology: new approaches to regional interaction. Oxford University Press, Oxford, pp 125-150. https://doi.org/10.1093/acprof: oso/9780199697090.003.0006

Scheidel W (2014) The shape of the Roman world: modelling Imperial connectivity. J Roman Archaeol 27:7-32. https://doi.org/10.1017/S1047759414001147

Soule RG, Goldman RF (1972) Terrain coefficients for energy cost prediction. J Appl Physiol 32:706-708. https://doi.org/10.1152/jappl.1972.32.5.706

Stančič Z, Veljanovski T (2000) Understanding Roman settlement patterns through multivariate statistics and predictive modelling. In: Lock G (ed) Beyond the map. Archaeology and spatial technologies. IOS Press, Amsterdam, pp 147-156

Van der Heijden P (2016) Romeinse wegen in Nederland. Matrijs, Utrecht

Van Dinter M (2013) The Roman limes in the Netherlands: how a delta landscape determined the location of the military structures. Neth J Geosci 92:11-32. https://doi.org/10.1017/ S0016774600000251

Van Dinter M, Kooistra LI, Dütting MK, Van Rijn P, Cavallo C (2014) Could the local population of the lower rhine delta supply the Roman army? Part 2: modelling the carrying capacity using archaeological, palaeo-ecological and geomorphological data. J Archaeol Low Ctries 5:5-50

Van Lanen RJ (2017) Changing ways. Patterns of connectivity, habitation and persistence in Northwest European lowlands during the first millennium AD. Utrecht University, Utrecht

Van Lanen RJ, Groenewoudt BJ, Spek T, Jansma E (2016) Route persistence. Modelling and quantifying historical route-network stability from the Roman period to early-modern times (AD 100-1600): a case study from the Netherlands. Archaeol Anthropol Sci 8. https://doi. org/10.1007/s12520-016-0431-z 
Verhagen P (2007) Case studies in archaeological predictive modelling. Leiden University Press, Leiden. https://doi.org/10.5117/9789087280079

Verhagen P (2013) On the road to nowhere? Least cost paths, accessibility and the predictive modelling perspective. In Contreras F, Farjas M, Melero FJ (eds) Fusion of cultures. Proceedings of the 38th annual conference on computer applications and quantitative methods in archaeology, Granada, Spain, April 2010. Archaeopress, Oxford, pp 383-389

Verhagen P, Brughmans T, Nuninger L, Bertoncello F (2013) The long and winding road: combining least cost paths and network analysis techniques for settlement location analysis and predictive modelling. In Earl G, Sly T, Chrysanthi A, Murrieta-Flores P, Papadopoulos C, Romanowska I, Wheatley D (eds) CAA2012. Proceedings of the 40th conference in computer applications and quantitative methods in archaeology, Southampton, United Kingdom, 26-30 March 2012. Pallas Publications, Amsterdam, pp 357-366

Verhagen P, Polla S, Frommer I (2014) Finding Byzantine junctions with Steiner trees. In: Polla $\mathrm{S}$, Verhagen $\mathrm{P}$ (eds) Computational approaches to the study of movement in archaeology. De Gruyter, Berlin, pp 73-97. https://doi.org/10.1515/9783110288384.73

Verhagen P, Vossen I, Groenhuijzen MR, Joyce JA (2016) Now you see them, now you don't: defining and using a flexible chronology of sites for spatial analysis of Roman settlement in the Dutch river area. J Archaeol Sci Rep 10:309-321. https://doi.org/10.1016/j.jasrep.2016.10.006

Vos PC (2015) Origin of the Dutch coastal landscape. Long-term landscape evolution of the Netherlands during the Holocene, Described and visualized in national, regional and local palaeogeographic map series. Barkhuis, Groningen. https://doi.org/10.2307/j.ctt2204s8d

Vos PC, De Vries S (2013) 2e generatie paleogeografische kaarten van Nederland (versie 2.0). Deltares, Utrecht

Vos PC, Gerrets DA (2005) Archaeology: a major tool in the reconstruction of the coastal evolution of Westergo (Northern Netherlands). Quat Int 133-134:61-75. https://doi.org/10.1016/j. quaint.2004.10.008

Vos WK (2009) Bataafs platteland. Het Romeinse nederzettingslandschap in het Nederlandse Kromme-Rijn gebied. Rijksdienst voor het Cultureel Erfgoed, Amersfoort

Wheatley D, Gillings M (2002) Spatial technology and archaeology. The archaeological application of GIS. CRC Press, London. https://doi.org/10.4324/9780203302392

Wilensky U (1999) NetLogo (and NetLogo user manual). Northwestern University, Evanston (IL)

Willems WJH (1986) Romans and Batavians. A regional study in the Dutch eastern river area. University of Amsterdam, Amsterdam

Zakšek K, Fovet E, Nuninger L, Podobnikar T (2008) Path modelling and settlement pattern. In Posluschny A, Lambers K, Herzog I (eds) Layers of perception: Proceedings of the 35th international conference on computer applications and quantitative methods in archaeology (CAA). Berlin, Germany, April 2-6, 2007. Dr. Rudolf Habelt GmbH, Bonn, pp 309-315

Open Access This chapter is licensed under the terms of the Creative Commons Attribution 4.0 International License (http://creativecommons.org/licenses/by/4.0/), which permits use, sharing, adaptation, distribution and reproduction in any medium or format, as long as you give appropriate credit to the original author(s) and the source, provide a link to the Creative Commons licence and indicate if changes were made.

The images or other third party material in this chapter are included in the chapter's Creative Commons licence, unless indicated otherwise in a credit line to the material. If material is not included in the chapter's Creative Commons licence and your intended use is not permitted by statutory regulation or exceeds the permitted use, you will need to obtain permission directly from the copyright holder.

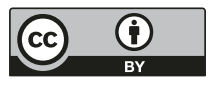

